Recibido 20 de julio, 2016 - Aceptado 15 de agosto, 2015

\title{
Eficacia de un enjuagatorio comercial en comparación al enjuagatorio con cloruro de sodio al 5\% en la disminución de Streptococcus mutans
}

\section{Effectiveness of a commercial mouthwash compared to mouthwash with sodium chloride, 5\% decrease Streptococcus mutans}

\author{
César Cayo, Sandra Salvador, Javier Ramos ${ }^{3}$
}

\section{RESUMEN}

El presente trabajo tiene como finalidad determinar el nivel de eficacia del enjuagatorio comercial en comparación con el enjuagatorio con cloruro de sodio al $5 \%$ en la disminución del Streptococcus mutans en la placa dentobacteriana. El grupo experimental evaluado estuvo constituido de 45 alumnos del $2^{\circ}$ de secundaria del Centro Educativo Félix B. Cárdenas. Los participantes se agruparon al azar, de la siguiente manera: Grupo $\mathrm{n}^{\circ} 01$ uso el Enjuagatorio comercial, Grupo $\mathrm{n}^{\circ} 02$ usaron Cloruro de Sodio al $5 \%$ y el Grupo $n^{\circ} 03$ usaron solo pasta dental. El método fue explicativo, aplicada, experimental y estadístico. De acuerdo a los resultados obtenidos de manera experimental se evaluó en 4 fechas en un periodo de 21 días, por lo que se determinó que existe eficacia del enjuagatorio comercial en comparación con el cloruro de Sodio al 5\% en la disminución del Streptococcus mutans en la placa bacteriana.

Palabras Claves: Enjuagatorio, agar mitis salivarius, placa dentobacteriana, cloruro de sodio.

\section{ABSTRACT}

This study aimed to determine the level of performance of commercial mouthwash compared with sodium chloride 5\% decrease in Streptococcus mutans in plaque. The evaluated experimental group consisted of 45 students of 2nd junior high Félix Cárdenas B. Education Center. Participants were randomly grouped as follows: Group $\mathrm{n}^{\circ} 01$ use commercial mouthwashes, Group ${ }^{\circ} 02$ used Sodium Chloride $5 \%$ and $n{ }^{\circ} 03$ group were used only toothpaste. The method was explanatory, applied, experimental and statistical. According to the results obtained experimentally assessed in four dates in a 21 day period, so it was determined that there efficacy of commercial mouthwash compared to sodium chloride, $5 \%$ decrease of Streptococcus mutans in the plaque

Keys words: Mouthwash, mitis salivarius agar, dentobacteriana plate, sodium chloride.

(1)Docente de Patología Bucal y Embriología e Histología General y Estomatológica de la EP de Estomatología de la UAP Filial Huacho. cesarcayorojas@gmail.com

(2)Cirujano Dentista,

(3)Coordinador de la EP de Estomatología Filial Huacho y docente de Medicina Estomatológica en la UAP Filial Huacho 


\section{INTRODUCCIÓN}

En reiteradas ocasiones la Organización Mundial de la Salud (OMS) y la Organización Panamericana de la Salud (OPS) han expresado que la caries dental es una enfermedad infecciosa que afecta la salud en general y la calidad de vida de las personas.

Por ello se han realizado diferentes investigaciones durante los últimos anos con la finalidad de disminuir la caries.

Entre las relacionadas con nuestra investigación tenemos:

En año 2013, Cayo R. Cesar et al. determinaron el mejor agente anticaries midiendo la eficacia de la aplicación del cepillado con cloruro de sodio diluido en agua al 5\%, pasta dental convencional y agua sola en la disminución del Streptococcus mutans presente en la placa dental en una población de 30 alumnos del 2 do ciclo de la Universidad Alas Peruanas.

Obteniendo como resultados que los tres métodos de cepillado reducen considerablemente el número de colonias, sin embargo es el grupo que se cepilló con cloruro de sodio diluido al 5\% quien reduce más el número de colonias al finalizar el tratamiento a la tercera semana de evaluación.(1)

En el año 2010, Sharma N evaluó la eficacia antiplaca / antigingivitis de un enjuague bucal que contienen aceites esenciales en comparación con un enjuague bucal $0,05 \%$ de cloruro de cetilpiridino en sujetos sanos en general en un tiempo de seis meses.

En este estudio se demostró la superioridad del grupo de aceites esenciales, en comparación con un $0.05 \%$ de cloruro de cetilpiridinio para reducir la placa y la gingivitis y confirmó que el uso diario de un enjuague bucal que contiene aceites esenciales puede proporcionar un beneficio clínicamente significativo en la reducción de la placa y la gingivitis.(2)
En el año 2010, Rupesh. S. et. al realizaron un estudio de evaluación comparativa de los efectos de un enjuague bucal que contiene alumbre y un enjuague con solución salina saturada en los niveles salivales de streptococcus mutans, este trabajo se realizó en niños tomando las muestras a los 10 y 21 días.

Después de los 21 días, los grupos de enjuague con solución salina saturada y el enjuague con alumbre mostraron diferencias significativas sobre el grupo de enjuague con placebo, demostrando una vez más que el grupo con enjuague de alumbre mostro una diferencia estadísticamente significativa sobre el grupo de enjuague con solución salina saturada.(3)

En el año 2006, John C. Gunsolley, realizo una revisión sistemática de la literatura para evaluar la eficacia de los productos antigingivitis y antiplaca en ensayos de seis meses de duración.

Diecisiete estudios sostenían los efectos antiplaca y antigingivitis de dentífricos que contenían 0,30\% de triclosán, 2,0\% de copolímero Gantrez. El mayor cuerpo de estudios apoyaba la eficacia de los enjuagues con aceites esenciales.

Un grupo menos numeroso de estudios avalaba un potente efecto antiplaca y antigingivitis del enjuague con $0,12 \%$ de clorhexidina. Los resultados de los enjuagues con cloruro de cetilpiridina variaron y dependían de la fórmula de los productos.

Los estudios de esta revisión sistemática evidencian notablemente los efectos antiplaca y antigingivitis de múltiples agentes.(4)

En el año 2005, Díaz S. Ana et al. estudiaron los efectos de los colutorios orales con fluoruro de sodio al $0,05 \%$ y agua con sal al $5 \%$ sobre la placa bacteriana y el ph salival en una población de soldados del ejército.

Los resultados del trabajo de investigación indicaron que tanto el colutorio con fluoruro de so- 
dio al 0,05\% como el colutorio con agua con sal al 5\% se comportan de maneras similar sobre la placa bacteriana, disminuyéndola al cabo de 40 días; mientras que ninguno de los colutorios fue capaz de alterar el $\mathrm{PH}$ salival en formas significativas. (5)

Por ello este trabajo de investigación pretende aportar a la odontología una alternativa, como es el uso de colutorio a base de cloruro de sodio al $5 \%$ con beneficios favorables y económicamente accesibles, para así disminuir colonias de Streptococcus mutans presentes en la placa dentobacteriana y poder mejorar la salud bucodental.

Por ello es que nos planteamos el siguiente problema: ¿Cuál es el nivel de eficacia de un enjuagatorio comercial en comparación al enjuagatorio con cloruro de sodio al 5\% en la disminución del Streptococcus mutans en la placa dentobacteriana?

La hipótesis principal planteada es: El enjuagatorio comercial presentaría mayor nivel de eficacia en comparación con el enjuagatorio con cloruro de sodio al $5 \%$ en la disminución de colonias Streptococcus mutans en la placa dentobacteriana.

Las hipótesis derivadas son 9:

1) Existirá una disminución de colonias de Streptococcus mutans de la placa dentobacteriana a los 7 días de aplicar el enjuagatorio comercial en los alumnos del Centro Educativo Estatal "Félix B. Cárdenas".

2) Existirá una disminución de colonias de Streptococcus mutans de la placa dentobacteriana a los 7 días de aplicar el enjuagatorio con Cloruro de sodio al 5\% en los alumnos del Centro Educativo Estatal "Félix B. Cárdenas".

3) Existirá una disminución de colonias de Streptococcus mutans de la placa dentobacteriana a los 14 días de aplicar el enjuagatorio comercial en los alumnos del Centro Educativo Estatal "Félix B. Cárdenas".
4) Existirá una disminución de colonias de Streptococcus mutans de la placa dentobacteriana a los 14 días de aplicar el enjuagatorio con Cloruro de sodio al 5\% en los alumnos del Centro Educativo Estatal "Félix B. Cárdenas".

5) Existirá una disminución de colonias de Streptococcus mutans de la placa dentobacteriana a los 21 días de aplicar el enjuagatorio comercial en los alumnos del Centro Educativo Estatal "Félix B. Cárdenas".

6) Existirá una disminución de colonias de Streptococcus mutans de la placa dentobacteriana a los 21 días de aplicar el enjuagatorio con cloruro de sodio al 5\% en los alumnos del Centro Educativo Estatal "Félix B. Cárdenas".

7) El enjuagatorio comercial presentaría un alto nivel de eficacia en la disminución del Streptococcus mutans en la placa dentobacteriana al compararlo con el grupo control.

8) El enjuagatorio con cloruro de sodio al 5\% presentaría un moderado nivel de eficacia en la disminución del Streptococcus mutans en la placa dentobacteriana al compararlo con el grupo control.

9) El enjuagatorio comercial presentaría una mayor eficacia en comparación al enjuagatorio con cloruro de sodio al 5\% en la disminución del Streptococcus mutans en la placa dentobacteriana.

Como objetivo principal se planteó el siguiente: Determinar el nivel de eficacia del enjuagatorio comercial en comparación con el enjuagatorio con cloruro de sodio al 5\% en la disminución del Streptococcus mutans en la placa dentobacteriana.

Los objetivos específicos son 9:

1) Determinar el número de colonias de Streptococcus mutans de la placa dentobacteriana a los 7 días de aplicar el enjuagatorio comercial en los 
alumnos del Centro Educativo Estatal "Félix B. Cárdenas".

2) Determinar el número de colonias de Streptococcus mutans de la placa dentobacteriana a los 7 días de aplicar el enjuagatorio con cloruro de sodio al 5\% en los alumnos del Centro Educativo Estatal "Félix B. Cárdenas".

3) Determinar el número de colonias de Streptococcus mutans de la placa dentobacteriana a los 14 días de aplicar el enjuagatorio comercial en los alumnos del Centro Educativo Estatal "Félix B. Cárdenas".

4) Determinar el número de colonias de Streptococcus mutans de la placa dentobacteriana a los 14 días de aplicar el enjuagatorio con cloruro de sodio al 5\% en los alumnos del Centro Educativo Estatal "Félix B. Cárdenas".

5) Determinar el número de colonias de Streptococcus mutans de la placa dentobacteriana a los 21 días de aplicar el enjuagatorio comercial en los alumnos del Centro Educativo Estatal "Félix B. Cárdenas".

6) Determinar el número de colonias de Streptococcus mutans de la placa dentobacteriana a los 21 días de aplicar el enjuagatorio con cloruro de sodio al 5\% en los alumnos del Centro Educativo Estatal "Félix B. Cárdenas".

7) Determinar la eficacia del enjuagatorio comercial en la disminución del Streptococcus mutans en la placa dentobacteriana al compararlo con el grupo control.

8) Determinar la eficacia del enjuagatorio con cloruro de sodio al $5 \%$ en la disminución de Streptococcus mutans en la placa dentobacteriana al compararlo con el grupo control.

9) Determinar la comparación de nivel de eficacia del el enjuagatorio comercial en comparación al enjuagatorio con el cloruro de sodio al $5 \%$ en la disminución de Streptococcus mutans en la placa dentobacteriana.
En la presente investigación se determinó como principal limitación a la escasez de trabajos de investigación con respecto al Enjuagatorio con cloruro de sodio al 5\% como agente reductor de colonias de Streptococcus mutans en la placa dentobacteriana.

\section{MATERIALES Y MÉTODOS}

El presente trabajo es experimental de tipo comparativo, tomando como muestra a 45 alumnos con edades entre 13 y 15 años de edad del 2 do año del nivel secundario del Centro Educativo Estatal "Félix B. Cárdenas" ubicado en el Distrito de Santa María - Huaura, luego se procedió a formar 3 grupos de 15 alumnos cada uno (aplicación del enjuagatorio comercial, cloruro de sodio al 5\% y pasta dental) y se empleó la prueba t para comparación de promedios, y prueba levene para igualdad de varianzas, ambas desarrolladas al 95 $\%$ de confianza.

\section{RESULTADOS}

Gráfico $\mathrm{N}^{\circ} 1$ : Promedios de los tipos de enjuagatorios agrupados por día de aplicación

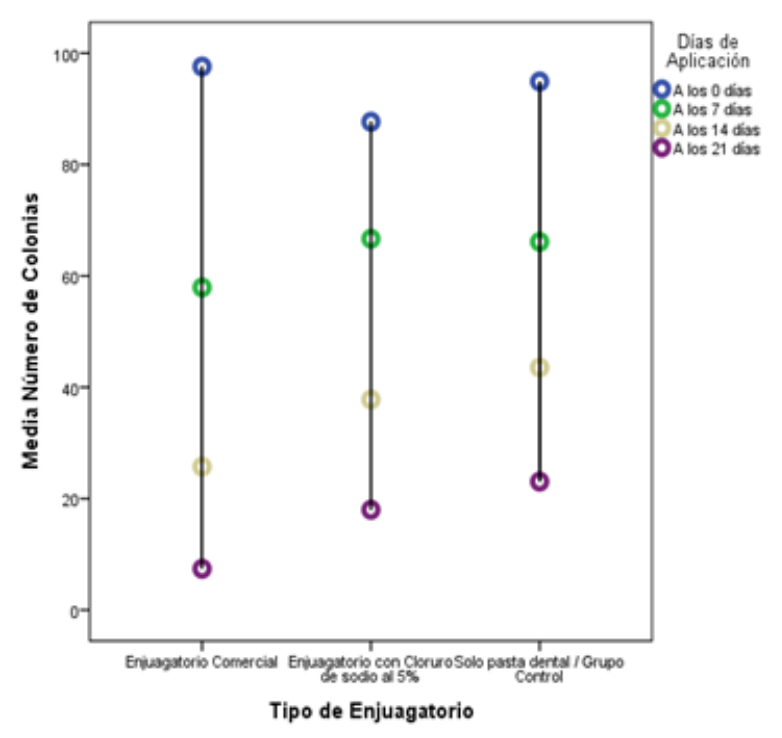


Tabla 1: Promedios de los tipos de enjuagatorios agrupados por día de aplicación

\begin{tabular}{|c|c|c|c|c|c|}
\hline & & & & & Media \\
\hline \multirow{12}{*}{$\begin{array}{c}\text { Tipo de } \\
\text { cnjuagatorio }\end{array}$} & \multirow{4}{*}{$\begin{array}{c}\text { Enjuagatorio } \\
\text { comercial }\end{array}$} & \multirow{4}{*}{$\begin{array}{c}\text { Días de } \\
\text { aplicación }\end{array}$} & A los 0 días & $\begin{array}{c}\text { Número de } \\
\text { Colonias }\end{array}$ & 98 \\
\hline & & & A los 7 días & $\begin{array}{c}\text { Número de } \\
\text { Colonias }\end{array}$ & 58 \\
\hline & & & A los 14 días & $\begin{array}{c}\text { Número de } \\
\text { Colonias }\end{array}$ & 26 \\
\hline & & & A los 21 días & $\begin{array}{c}\text { Número de } \\
\text { Colonias }\end{array}$ & 7 \\
\hline & \multirow{4}{*}{$\begin{array}{l}\text { Enjuagatorio } \\
\text { con cloruro de } \\
\text { sodio al 5\% }\end{array}$} & \multirow{4}{*}{$\begin{array}{c}\text { Días de } \\
\text { aplicación }\end{array}$} & A los 0 días & $\begin{array}{c}\text { Número de } \\
\text { Colonias }\end{array}$ & 88 \\
\hline & & & A los 7 días & $\begin{array}{c}\text { Número de } \\
\text { Colonias }\end{array}$ & 67 \\
\hline & & & A los 14 días & $\begin{array}{c}\text { Número de } \\
\text { Colonias }\end{array}$ & 38 \\
\hline & & & A los 21 días & $\begin{array}{c}\text { Número de } \\
\text { Colonias }\end{array}$ & 18 \\
\hline & \multirow{4}{*}{$\begin{array}{c}\text { Solo pasta } \\
\text { dental / Grupo } \\
\text { control }\end{array}$} & \multirow{4}{*}{$\begin{array}{c}\text { Días de } \\
\text { aplicación }\end{array}$} & A los 0 días & $\begin{array}{c}\text { Número de } \\
\text { Colonias }\end{array}$ & 95 \\
\hline & & & A los 7 días & $\begin{array}{c}\text { Número de } \\
\text { Colonias }\end{array}$ & 66 \\
\hline & & & A los 14 días & $\begin{array}{c}\text { Número de } \\
\text { Colonias }\end{array}$ & 44 \\
\hline & & & A los 21 días & $\begin{array}{c}\text { Número de } \\
\text { Colonias }\end{array}$ & 23 \\
\hline
\end{tabular}

Tabla 2: Existirá una disminución de colonias de Streptococcus mutans de la placa dentobacteriana a los 7 días de aplicar el enjuagatorio comercial.

Estadísticos de grupo. Enjuagatorio Comercial (a los 7 dias)

\begin{tabular}{|c|c|c|c|c|c|}
\hline & Días de Aplicación & $\mathrm{N}$ & Media & Desviación típ. & Error típ. de la media \\
\hline \multirow[t]{2}{*}{ Número de Colonias } & A los 0 días & 15 & 97,60 & 35,506 & 9,168 \\
\hline & A los 7 días & 15 & 57,93 & 26,626 & 6,875 \\
\hline
\end{tabular}

Prueba de muestras independientes. Enjuagatorio Comercial

\begin{tabular}{|c|c|c|c|c|c|c|c|c|c|c|}
\hline \multirow{3}{*}{$\begin{array}{c}\text { Variables } \\
\text { dependientes }\end{array}$} & \multirow[b]{3}{*}{ Supuestos } & \multicolumn{2}{|c|}{$\begin{array}{l}\text { Prueba de Levene para } \\
\text { la igualdad de varianzas }\end{array}$} & \multicolumn{7}{|c|}{ Prueba $T$ para la igualdad de medias } \\
\hline & & \multirow[b]{2}{*}{$\mathrm{F}$} & \multirow[b]{2}{*}{ Sig. } & \multirow[b]{2}{*}{$\mathrm{t}$} & \multirow[b]{2}{*}{ gl } & \multirow{2}{*}{$\begin{array}{c}\text { Sig. } \\
\text { (bilateral) }\end{array}$} & \multirow{2}{*}{$\begin{array}{l}\text { Diferencia } \\
\text { de medias }\end{array}$} & \multirow{2}{*}{$\begin{array}{c}\text { Error típ. de la } \\
\text { diferencia }\end{array}$} & \multicolumn{2}{|c|}{$\begin{array}{l}95 \% \text { Intervalo de } \\
\text { confianza para la } \\
\text { diferencia }\end{array}$} \\
\hline & & & & & & & & & Inferior & Superior \\
\hline $\begin{array}{l}\text { Número de } \\
\text { Colonias }\end{array}$ & $\begin{array}{l}\text { Se han asumido } \\
\text { varianzas iguales }\end{array}$ & 1,071 & 0,310 & 3,462 & 28 & 0,002 & 39,667 & 11,459 & 16,194 & 63,139 \\
\hline & $\begin{array}{l}\text { No se han asumido } \\
\text { varianzas iguales }\end{array}$ & & & 3,462 & 25,963 & 0,002 & 39,667 & 11,459 & 16,111 & 63,223 \\
\hline
\end{tabular}


Tabla 3: Existirá una disminución de colonias de Streptococcus mutans de la placa dentobacteriana a los 7 días de aplicar el enjuagatorio con Cloruro de sodio al 5\%

Estadísticos de grupo. Cloruro de Sodio al $5 \%$ (a los 7 días

\begin{tabular}{|c|c|c|c|c|c|}
\hline & Días de Aplicación & $\mathrm{N}$ & Media & Desviación típ. & Error típ. de la media \\
\hline \multirow{2}{*}{ Número de Colonias } & A los 0 días & 15 & 87,67 & 30,698 & 7,926 \\
\hline & A los 7 días & 15 & 66,67 & 29,183 & 7,535 \\
\hline
\end{tabular}

Prueba de muestras independientes. Cloruro de Sodio al $5 \%$

\begin{tabular}{|c|c|c|c|c|c|c|c|c|c|c|}
\hline & \multicolumn{2}{|c|}{$\begin{array}{c}\text { Prueba de Levene } \\
\text { para la igualdad de } \\
\text { varianzas }\end{array}$} & \multicolumn{7}{|c|}{ Prueba T para la igualdad de medias } \\
\hline & & \multirow[b]{2}{*}{$\mathrm{F}$} & \multirow[b]{2}{*}{ Sig. } & \multirow[b]{2}{*}{$\mathrm{t}$} & \multirow[b]{2}{*}{ gl } & \multirow{2}{*}{$\begin{array}{c}\text { Sig. } \\
\text { (bilateral } \\
\text { ) }\end{array}$} & \multirow{2}{*}{$\begin{array}{l}\text { Diferencia } \\
\text { de medias }\end{array}$} & \multirow{2}{*}{$\begin{array}{l}\text { Error típ. de } \\
\qquad \text { la } \\
\text { diferencia }\end{array}$} & \multicolumn{2}{|c|}{$\begin{array}{l}95 \% \text { Intervalo de } \\
\text { confianza para la } \\
\text { diferencia }\end{array}$} \\
\hline & & & & & & & & & Inferior & Superior \\
\hline $\begin{array}{l}\text { Número } \\
\text { de } \\
\text { Colonias }\end{array}$ & $\begin{array}{l}\text { Se han asumido } \\
\text { varianzas iguales } \\
\text { No se han asumido } \\
\text { varianzas iguales }\end{array}$ &, 001 & ,981 & $\begin{array}{l}1,920 \\
1,920\end{array}$ & $\begin{array}{r}28 \\
27,929\end{array}$ &, 065 & 21,000 & 10,936 & $\begin{array}{l}-1,402 \\
-1,405\end{array}$ & $\begin{array}{l}43,402 \\
43,405\end{array}$ \\
\hline
\end{tabular}

Tabla 4: Existirá una disminución de colonias de Streptococcus mutans de la placa dentobacteriana a los 14 días de aplicar el enjuagatorio comercial.

Estadísticos de grupo. Enjuagatorio Comercial (a los 14 días)

\begin{tabular}{|c|c|c|c|c|c|}
\hline & Díss de Aplicación & $\mathrm{N}$ & Medis & Desvisción típ. & $\begin{array}{l}\text { Error típ. de ls } \\
\text { medis }\end{array}$ \\
\hline Número de Coloniss & $\begin{array}{l}\text { A los } 0 \text { dias } \\
\text { A los } 14 \text { días }\end{array}$ & $\begin{array}{l}15 \\
15\end{array}$ & $\begin{array}{l}97,60 \\
25,73\end{array}$ & $\begin{array}{r}35,506 \\
12,948\end{array}$ & $\begin{array}{l}9.168 \\
3.343\end{array}$ \\
\hline
\end{tabular}

Prueba de muestras independientes

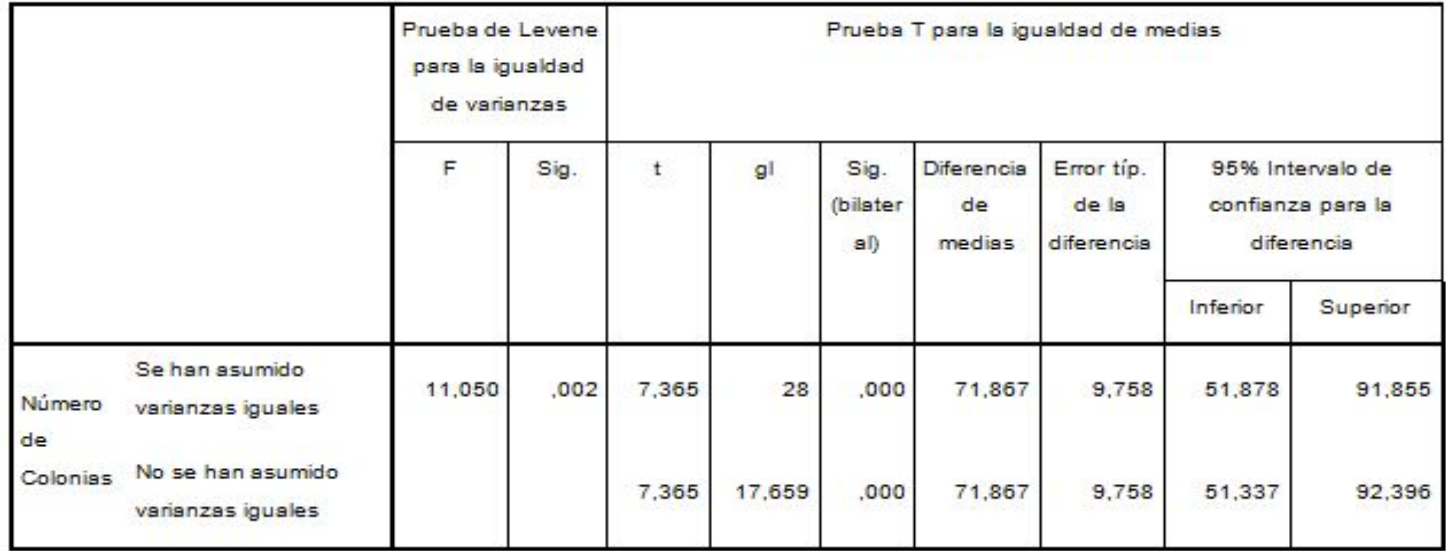


Tabla 5: Existirá una disminución de colonias de Streptococcus mutans de la placa dentobacteriana a los 14 días de aplicar el enjuagatorio con Cloruro de sodio al 5\%

Estadísticos de grupo. Cloruro de Sodio al $5 \%$ (a los 14 días)

\begin{tabular}{|ll|r|r|r|r|}
\hline & Días de Aplicación & N & Media & Desviación típ. & $\begin{array}{c}\text { Error típ. de la } \\
\text { media }\end{array}$ \\
\hline \multirow{2}{*}{ Número de Colonias } & A los 0 días & 15 & 87,67 & 30,698 & 7,926 \\
& A los 14 días & 15 & 37,80 & 21,109 & 5,450 \\
\hline
\end{tabular}

Prueba de muestras independientes

\begin{tabular}{|c|c|c|c|c|c|c|c|c|c|c|}
\hline & & \multicolumn{2}{|c|}{$\begin{array}{c}\text { Prueba de Levene } \\
\text { para la igualdad de } \\
\text { varianzas }\end{array}$} & \multicolumn{7}{|c|}{ Prueba T para la igualdad de medias } \\
\hline & & \multirow[t]{2}{*}{$\mathrm{F}$} & \multirow[t]{2}{*}{ Sig. } & \multirow[t]{2}{*}{$\mathrm{t}$} & \multirow[t]{2}{*}{ gl } & \multirow[t]{2}{*}{$\begin{array}{c}\text { Sig. } \\
\text { (bilater } \\
\text { al) }\end{array}$} & \multirow[t]{2}{*}{$\begin{array}{l}\text { Diferencia } \\
\text { de medias }\end{array}$} & \multirow{2}{*}{$\begin{array}{l}\text { Error típ. } \\
\text { de la } \\
\text { diferenci } \\
\text { a }\end{array}$} & \multicolumn{2}{|c|}{$\begin{array}{c}95 \% \text { Intervalo de } \\
\text { confianza para la } \\
\text { diferencia }\end{array}$} \\
\hline & & & & & & & & & Inferior & Superior \\
\hline $\begin{array}{l}\text { Número de } \\
\text { Colonias }\end{array}$ & $\begin{array}{l}\text { Se han asumido } \\
\text { varianzas iguales } \\
\text { No se han asumido } \\
\text { varianzas iguales }\end{array}$ & 2,417 & , 131 & 5,184 & 24,820 &, 000 & 49,867 & 9,619 & 30,162 & 69,571 \\
\hline
\end{tabular}

Tabla 6: Existirá una disminución de colonias de Streptococcus mutans de la placa dentobacteriana a los 21 días de aplicar el enjuagatorio comercial.

Estadísticos de grupo. Enjuagatorio Comercial (a los 21 días)

\begin{tabular}{|ll|r|r|r|r|}
\hline & Días de Aplicación & N & Media & Desviación típ. & Error típ. dela media \\
\hline Número de Colonias & A los 0 días & 15 & 97,60 & 35,506 & 9,168 \\
& A los 21 días & 15 & 7,40 & 3,247 &, 838 \\
\hline
\end{tabular}

Prueba de muestras independientes

\begin{tabular}{|c|c|c|c|c|c|c|c|c|c|c|}
\hline & & \multicolumn{2}{|c|}{$\begin{array}{c}\text { Prueba de Levene } \\
\text { para la igualdad de } \\
\text { varianzas }\end{array}$} & \multicolumn{7}{|c|}{ Prueba T para la igualdad de medias } \\
\hline & & \multirow[t]{2}{*}{$\mathrm{F}$} & \multirow[t]{2}{*}{ Sig. } & \multirow[t]{2}{*}{$\mathrm{t}$} & \multirow[t]{2}{*}{ gl } & \multirow[t]{2}{*}{$\begin{array}{c}\text { Sig. } \\
\text { (bilateral) }\end{array}$} & \multirow[t]{2}{*}{$\begin{array}{c}\text { Diferenci } \\
\text { a de } \\
\text { medias }\end{array}$} & \multirow[t]{2}{*}{$\begin{array}{l}\text { Error típ. } \\
\text { de la } \\
\text { diferencia }\end{array}$} & \multicolumn{2}{|c|}{$\begin{array}{c}95 \% \text { Intervalo de } \\
\text { confianza para la } \\
\text { diferencia }\end{array}$} \\
\hline & & & & & & & & & Inferior & Superior \\
\hline \multirow{2}{*}{$\begin{array}{l}\text { Número de } \\
\text { Colonias }\end{array}$} & $\begin{array}{l}\text { Se han asumido } \\
\text { varianzas iguales }\end{array}$ & 24,524 &, 000 & 9,798 & 28 &, 000 & 90,200 & 9,206 & 71,343 & 109,057 \\
\hline & $\begin{array}{l}\text { No se han asumido } \\
\text { varianzasiguales }\end{array}$ & & & 9,798 & 14,234 &, 000 & 90,200 & 9,206 & 70,486 & 109,914 \\
\hline
\end{tabular}


Tabla 7: Existirá una disminución de colonias de Streptococcus mutans de la placa dentobacteriana a los 21 días de aplicar el enjuagatorio con Cloruro de sodio al 5\%.

Estadísticos de grupo. Cloruro de Sodio al 5\% (a los 21 días)

\begin{tabular}{|c|c|c|c|c|c|}
\hline & Días de Aplicación & $\mathrm{N}$ & Media & Desviación típ. & $\begin{array}{l}\text { Error típ. de la } \\
\text { media }\end{array}$ \\
\hline Número de Colonias & $\begin{array}{l}\text { A los } 0 \text { días } \\
\text { A los } 21 \text { días }\end{array}$ & $\begin{array}{l}15 \\
15\end{array}$ & $\begin{array}{l}87,67 \\
18,00\end{array}$ & $\begin{array}{r}30,698 \\
12,183\end{array}$ & $\begin{array}{l}7,926 \\
3,146\end{array}$ \\
\hline
\end{tabular}

Prueba de muestras independientes

\begin{tabular}{|c|c|c|c|c|c|c|c|c|c|c|}
\hline & & \multicolumn{2}{|c|}{$\begin{array}{c}\text { Prueba de Levene } \\
\text { para la igualdad de } \\
\text { varianzas }\end{array}$} & \multicolumn{7}{|c|}{ Prueba T para la igualdad de medias } \\
\hline & & \multirow[t]{2}{*}{$\mathrm{F}$} & \multirow[t]{2}{*}{ Sig. } & \multirow[t]{2}{*}{$t$} & \multirow[t]{2}{*}{ gl } & \multirow[t]{2}{*}{$\begin{array}{c}\text { Sig. } \\
\text { (bilateral) }\end{array}$} & \multirow[t]{2}{*}{$\begin{array}{l}\text { Diferencia } \\
\text { de medias }\end{array}$} & \multirow[t]{2}{*}{$\begin{array}{l}\text { Error típ. de } \\
\text { la diferencia }\end{array}$} & \multicolumn{2}{|c|}{$\begin{array}{c}95 \% \text { Intervalo de confianza } \\
\text { para la diferencia }\end{array}$} \\
\hline & & & & & & & & & Inferior & Superior \\
\hline $\begin{array}{l}\text { Número de } \\
\text { Colonias }\end{array}$ & $\begin{array}{l}\text { Se han asumido } \\
\text { varianzas iguales } \\
\text { No se han asumido } \\
\text { varianzas iguales }\end{array}$ & 10,776 &, 003 & 8,170 & 18,303 &, 000 & $\begin{array}{l}69,667 \\
69,667\end{array}$ & $\begin{array}{l}8,528 \\
8,528\end{array}$ & $\begin{array}{r}52,199 \\
51,772\end{array}$ & 87,135 \\
\hline
\end{tabular}

Tabla 8: El enjuagatorio comercial presentaría un alto nivel de eficacia en la disminución del Streptococcus mutans en la placa dentobacteriana al compararlo con el grupo control.

Estadísticos de grupo. Enjuagatorio Comercial en comparación con solo pasta dental (Grupo Control)

\begin{tabular}{|ll|r|r|r|r|}
\hline & Tipo de Enjuagatorio & N & Media & Desviación típ. & $\begin{array}{c}\text { Error típ. de la } \\
\text { media }\end{array}$ \\
\hline Número de Colonias & Enjuagatorio Comercial & 60 & 47,17 & 41,287 & 5,330 \\
& Solo pasta dental/Grupo Control & 60 & 56,92 & 37,185 & 4,800 \\
\hline
\end{tabular}

Prueba de muestras independientes

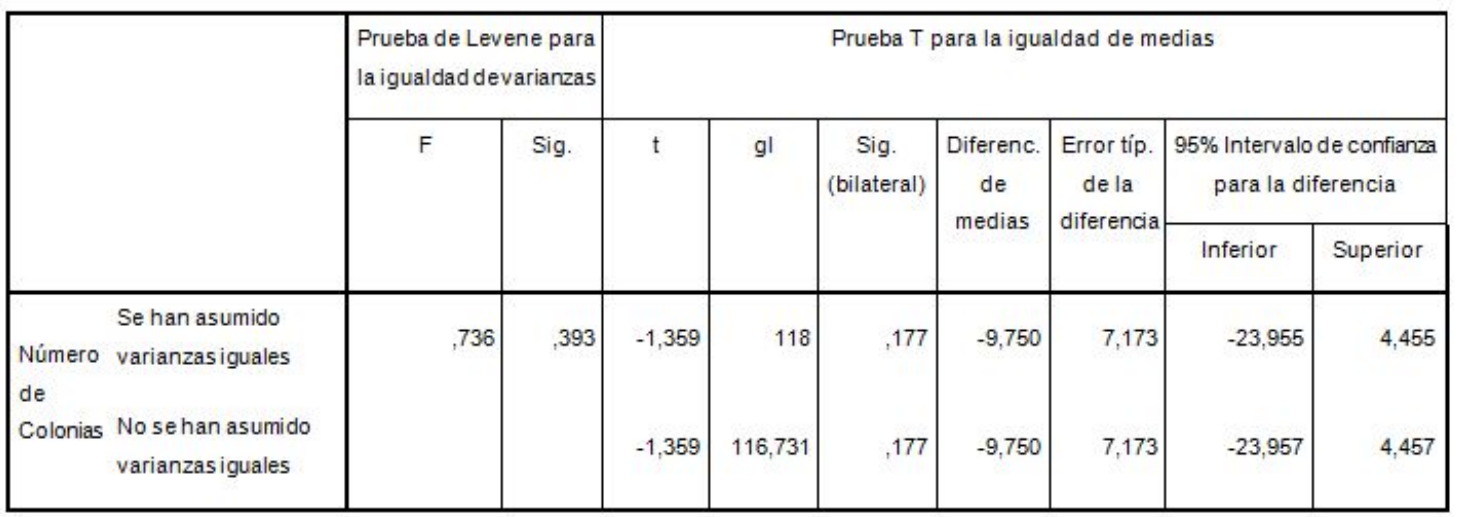


Tabla 9: El enjuagatorio con Cloruro de sodio al 5\% presentaría un moderado nivel de eficacia en la disminución del Streptococcus mutans en la placa dentobacteriana al compararlo con el grupo control.

Estadísticos de grupo. Cloruro de Sodio al $5 \%$ en comparación a solo pasta dental (grupo control)

\begin{tabular}{|ll|r|r|r|r|}
\hline Tipo de Enjuagatorio & N & Media & Desviación típ. & Error típ. dela media \\
\hline Enjuagatorio con Cloruro de sodio al & 60 & 52,53 & 35,912 & 4,636 \\
\hline Número de Colonias & $5 \%$ & 60 & 56,92 & 37,185 & 4,800 \\
\hline
\end{tabular}

Prueba de muestras independientes

\begin{tabular}{|c|c|c|c|c|c|c|c|c|c|c|}
\hline & & \multicolumn{2}{|c|}{$\begin{array}{l}\text { Prueba de Levene para la } \\
\text { igualdad de varianzas }\end{array}$} & \multicolumn{7}{|c|}{ Prueba T para la igualdad de medias } \\
\hline & & \multirow[t]{2}{*}{$\mathrm{F}$} & \multirow[t]{2}{*}{ Sig. } & \multirow[t]{2}{*}{$\mathrm{t}$} & \multirow[t]{2}{*}{ gl } & \multirow{2}{*}{$\begin{array}{c}\text { Sig. } \\
\text { (bilateral } \\
\text { ) }\end{array}$} & \multirow[t]{2}{*}{$\begin{array}{c}\text { Diferencia de } \\
\text { medias }\end{array}$} & \multirow{2}{*}{$\begin{array}{c}\text { Error típ. } \\
\text { de la } \\
\text { diferencia }\end{array}$} & \multicolumn{2}{|c|}{$\begin{array}{c}95 \% \text { Intervalo de confianza } \\
\text { para la diferencia }\end{array}$} \\
\hline & & & & & & & & & Inferior & Superior \\
\hline $\begin{array}{l}\text { Número de } \\
\text { Colonias }\end{array}$ & $\begin{array}{l}\text { Se han asumido } \\
\text { varianzas iguales } \\
\text { No se han asumido } \\
\text { varianzas iguales }\end{array}$ &, 044 &, 833 & $\begin{array}{l}-, 657 \\
-, 657\end{array}$ & $\begin{array}{r}118 \\
117,85 \\
7\end{array}$ &, 513 & $\begin{array}{l}-4,383 \\
-4,383\end{array}$ & $\begin{array}{l}6,674 \\
6,674\end{array}$ & $\begin{array}{l}-17,599 \\
-17,599\end{array}$ & $\begin{array}{l}8,832 \\
8,833\end{array}$ \\
\hline
\end{tabular}

Tabla 10: El enjuagatorio comercial presentaría una mayor eficacia en comparación al enjuagatorio con Cloruro de sodio al 5\% en la disminución del Streptococcus mutans en la placa dentobacteriana.

Estadísticos de grupo. Enjuagatorio comercial en comparación al Cloruro de Sodio al 5\%

\begin{tabular}{|ll|r|r|r|r|}
\hline & Tipo de Enjuagatorio & N & Media & Desviación típ. & Error típ. de la media \\
\hline Enjuagatorio Comercial & 60 & 47,17 & 41,287 & 5,330 \\
Número de Colonias & $\begin{array}{l}\text { Enjuagatorio con Cloruro de } \\
\text { Sodio al 5\% }\end{array}$ & 60 & 52,53 & 35,912 & 4,636 \\
\hline
\end{tabular}

Prueba de muestras independientes

\begin{tabular}{|c|c|c|c|c|c|c|c|c|c|c|}
\hline & & \multicolumn{2}{|c|}{$\begin{array}{l}\text { Prueba de Levene para } \\
\text { la igualdad devarianzas }\end{array}$} & \multicolumn{7}{|c|}{ Prueba T para la igualdad de medias } \\
\hline & & \multirow[t]{2}{*}{$\mathrm{F}$} & \multirow[t]{2}{*}{ Sig. } & \multirow[t]{2}{*}{$\mathrm{t}$} & \multirow[t]{2}{*}{ gl } & \multirow{2}{*}{\begin{tabular}{|c|} 
Sig. \\
(bilate \\
ral)
\end{tabular}} & \multirow{2}{*}{$\begin{array}{c}\text { Diferenci } \\
\text { a de } \\
\text { medias }\end{array}$} & \multirow[t]{2}{*}{$\begin{array}{l}\text { Error típ. de } \\
\text { la diferencia }\end{array}$} & \multicolumn{2}{|c|}{$\begin{array}{c}95 \% \text { Intervalo de confianza } \\
\text { para la diferencia }\end{array}$} \\
\hline & & & & & & & & & Inferior & Superior \\
\hline $\begin{array}{l}\text { Número de } \\
\text { Colonias }\end{array}$ & $\begin{array}{l}\text { Se han asumido } \\
\text { varianzas iguales } \\
\text { No se han asumido } \\
\text { varianzas iguales }\end{array}$ & 1,166 &, 282 & $\begin{array}{l}-, 760 \\
-, 760\end{array}$ & $\begin{array}{r}118 \\
115,776\end{array}$ &, 449 & $-5,367$ & 7,064 & $\begin{array}{l}-19,356 \\
-19,359\end{array}$ & 8,623 \\
\hline
\end{tabular}




\section{CONCLUSIONES}

1. Existe eficacia del enjuagatorio comercial en comparación con el cloruro de sodio en la disminución del Streptococcus mutans en la placa dentobacteriana.

2. Se determinó 58 unidades formadoras de colonias (UFC) de Streptococcus mutans a los 7 días de aplicar el enjuagatorio comercial en los alumnos del Centro Educativo Estatal "Félix B. Cárdenas".

3. Se determinó 67 unidades formadoras de colonias (UFC) de Streptococcus mutans a los 7 días de aplicar el cloruro de sodio al 5\% en los alumnos del Centro Educativo Estatal "Félix B. Cárdenas".

4. Se determinó 26 unidades formadoras de colonias (UFC) de Streptococcus mutans a los 14 días de aplicar el enjuagatorio comercial en los alumnos del Centro Educativo Estatal "Félix B. Cárdenas".

5. Se determinó 38 unidades formadoras de colonias (UFC) de Streptococcus mutans a los 14 días de aplicar el cloruro de sodio al 5\% en los alumnos del Centro Educativo Estatal "Félix B. Cárdenas".

6. Se determinó siete unidades formadoras de colonias (UFC) de Streptococcus mutans a los 21 días de aplicar el enjuagatorio comercial en los alumnos del Centro Educativo Estatal "Félix B. Cárdenas".

7. Se determinó 18 unidades formadoras de colonias (UFC) de Streptococcus mutans a los 21 días de aplicar el cloruro de sodio al 5\% en los alumnos del Centro Educativo Estatal "Félix B. Cárdenas".

8. El enjuagatorio comercial presenta un alto nivel de eficacia en la disminución del Streptococcus mutans en la placa dentobacteriana al compararlo con el grupo control.
9. El enjuagatorio con cloruro de sodio al 5\% presenta un moderado nivel de eficacia en la disminución del Streptococcus mutans en la placa dentobacteriana al compararlo con el grupo control.

10. El enjuagatorio comercial presenta una mayor eficacia en comparación al enjuagatorio con cloruro de sodio al $5 \%$ en la disminución del Streptococcus mutans en la placa dentobacteriana.

\section{DISCUSIÓN}

De acuerdo con las investigaciones citadas anteriormente, se muestran diversos estudios similares para controlar la placa bacteriana en el individuo.

Teniendo resultados análogos a nuestro estudio, como el de Sharma N, et, al en el año 2010 evaluó la eficacia antiplaca/ antigingivitis de un enjuague bucal que contiene aceites esenciales en comparación con un enjuague bucal $0.05 \%$ de cloruro de cetilpiridino, dando resultados positivos ya que indica que el uso diario de un enjuague bucal que contienen aceites esenciales puede proporcionar un beneficio clínicamente significativo en la reducción de la placa y la gingivitis(2).

Jhon C. Gunsolley (2006) evaluó la eficacia de los productos antigingivitis y antiplaca en ensayos de seis meses, obteniendo resultados favorables ya que los estudios de esta revisión sistemática evidencian notablemente los efectos antiplaca y antigingivitis de múltiples agentes(4), ambos trabajos corroboran nuestra investigación ya que existe una disminución notable en el número de colonias Streptococcus mutans de la placa dentobacteriana a partir de los 7 días de aplicar el enjuagatorio comercial.

Así tambien tenemos a Cayo C. et. al que en el año 2013 tuvo como objetivó determinar el mejor agente anticaries midiendo la eficacia de la aplicación del cepillo con cloruro de sodio diluido en agua al 5\%, pasta dental y agua sola, llegando a la conclusión que el grupo que se cepilló con 
cloruro de sodio diluido al $5 \%$ reduce considerablemente el número de colonias de streptococcus mutans(1).

Díaz S. Ana, et. al. en el año 2005 evaluó los efectos de dos colutorios orales (un colutorio con fluoruro de sodio al $0,05 \%$ y un colutorio de agua con sal al 5\%) sobre la placa bactriana y el $\mathrm{pH}$ salival, actuando de forma positiva, indicando que tanto el colutorio con fluoruro de sodio al $0,05 \%$ como el colutorio con agua con sal al 5\% se comportan de maneras similar sobre la placa bacteriana, disminuyéndola al cabo de 40 dias; significativas (5), en nuestro estudio el uso de cloruro de sodio al $5 \%$ actuó de manera moderada en la disminución de streptococcus mutans de la placa dentobacteriana.

Rupesh S. et. al en el año 2010 trató de evaluar y comparar los efectos del enjuague de solución salina saturada y un enjuague bucal de alumbre al 0,02 M en los niveles salivales de Streptococcus mutans en niños; obteniendo resultados positivos a los 10 días y a los 21 días después de aplicado el tratamiento. Después de 21 días, los grupos de enjuague con solución salina saturada y el enjuague de alumbre mostraron diferencias estadísticamente significativas sobre el grupo del enjuague placebo (3), corroborando nuestro estudio ya que tambien existió una disminución estadística en el número de colonias Streptococcus mutans de la placa dentobacteriana a los 21 días de aplicar el cloruro de sodio al 5\%.

Agradecimientos:

Al Dr. Segundo García Rodríguez por su apoyo incondicional en la realización de este trabajo brindando las facilidades académicas para el desarrollo del mismo, así como también a la $\mathrm{Mg}$ Ana Contreras Contreras por su apoyo en la asesoría microbiológica para desarrollar este trabajo.

\section{REFERENCIAS BIBLIOGRÁFICAS}

1.Cayo R. Cesar, Eficacia del cepillado con cloruro de sodio versus pasta dental en la disminución del Streptococcus mutans, Lima - Perú, talleres gráficos de la Universidad Alas Peruanas, 2013.

2.Sharma N, Superiority of an Essencial Oil mouthrinse when compared with a $0.05 \%$ cetylpyridinium chloride containing mouthrinse: A six - Month Study. Int Dent J. 2010.

3.Rupesh S, et al. Evaluación comparativa de los efectos de un enjuague bucal que contiene alumbre y un enjuague con solución salina saturada en los niveles salivales de Streptococcus mutans. Journal of Indian Society of Pedodontics and Preventive Dentistry. Jul - Sept 2010

4.Gunsolley J. A. Meta - Analysis of six month studies of antiplaque and antigingivitis agents. J Am Dent Assoc. 2006.

5.Díaz Soriano A., et al. Efectos de los colutorios orales con fluoruro de sodio al 0.05\% y agua con sal al 5\% sobre la placa bacteriana y el pH salival. Odontología San Marquina. 2005.

Cesar Cayo

Email: cesarcayorojas@gmail.com 